\title{
On the C-E Translation of Chinese Classics from the Perspective of Thick Translation Theory*
}

\author{
Yuying Li \\ Foreign Language College, Jiangxi Normal University, Nanchang City, China \\ Qi Lu \\ Foreign Language College, Jiangxi Normal University, Nanchang City, China
}

\begin{abstract}
Thick translation theory was put forward by Appiah, an American translation theorist, concerning the cultural information dissemination and cultural significance of a deep description. Based on the English translation version of Six Chapters of a Floating Life, the study analyses the manifestation of traditional Chinese culture and methods to translate Chinese classic words from the perspective of "thick translation" theory, in an attempt to verify the operability of the theory in the translation of Chinese classics.
\end{abstract}

Index Terms - thick translation, Six Chapters of a Floating Life, traditional culture

\section{INTRODUCTION}

As an inter-lingual communication, translation is not only a simple process of language conversion, but also an integration of two disparate cultures. In literary translation, especially in translation of Chinese classics, the target readers need to understand not only the meaning of the original text itself, but also more about the traditional Chinese culture involved. In the process of translating, the differences in language between English and Chinese and the cultural background behind them are quite different, so it is inevitable for translators to face some obstacles caused by cultural diversities. How to overcome these barriers is currently a conventional problem to be solved for the translation practice of Chinese classics.

Lin Yutang is known as the person with two feet individually stepping on the Chinese and West Cultures. The English version of Six Chapters of a Floating Life, one of his masterpieces, depicts the daily life of Shen Sanbai and his wife Chen Yun, including the art of living, scenic landscape, literary commentary on literature and art, as well as the description of traditional Chinese ethics and customs. In the preface, Lin Yutang praised Yun as "the most lovable woman in Chinese literature and Chinese history." When translating this book, he also boldly showed western readers how natural and innocent Yun was and how leisure their couple life was.

Thick translation is a translation theory related to cultural communication proposed by the American scholar Appiah in the early 1990s. The research explores the translation strategies taken by Lin Yutang in face of these ineluctable translation obstacles from the perspective of thick translation theory and analyzes the phenomenon of the manifestation of Chinese classical culture in the English version of Six Chapters of a Floating Life.

\section{LITERATURE REVIEW}

American cultural anthropologist Clifford Greertz, a representative figure who turns cultural anthropology from evolution to hermeneutics (hermeneutics of anthropology). In the book The Interpretation Cultures written by Greertz, he suggests that cultural studies are a theory of behavioral interpretation. The so-called culture is the web of significance that is compiled by people themselves. Therefore, the analysis of culture is a explanatory science of seeking significance rather than an experimental science that seeks regular rules. (Greertz, 1973) Presented the concept of "thick description" in 1973, Greertz considered human culture as a semiotic one which is a web and a context, and the meaning under the context can be expounded through "thick description."

With the enlightenment of "thick description", Kwame Anthony Appiah was the first one to introduce the notion of "thick" into translation study which was initially mentioned in his thesis of Thick Translation in Callaloo in 1993. At the beginning of the article, he discussed how to translate 7,000 proverbs of his hometown of Kumasi into English. From the angle of analytical philosophy, he analyzed the limitation of meaning transformation in the translation process by Gricean Mechanism.As defined by Appiah, thick translation is "a translation that seeks with its annotations and its accompanying glosses to locate the text in a rich cultural and linguistic context" (Appiah, 1993, p.817) from the perspective of cultural anthropology. In his view, thick translation makes the translated version to be contextualized, so the readers could understand the social and cultural context, and result in the grasp and respect for the other culture.

\footnotetext{
* Sponsored by On English Translation of Classics by Jiangxi Native Literati in Song Dynasty, a Social Science Planned Research Project of Jiangxi in 2015
} 
Therefore, thick translation can highlight the authenticity and legitimacy of culture and make the other culture to speak out their own voice. In Appiah's opinion, the purpose of abundantly adding explanatory text materials like footnotes, the aim of adding annotations and explanations into the target language text is to provide the readers with background information and to arouse an interest in the source language culture. Since the $20^{\text {th }}$ century, foreign studies on thick translation have thrived.

Theo Hermans is a scholar of University College London, who combined translation with other culture issues into deep discussion for the first time. In his Cross-cultural Studies as Thick Translation, Hermans gives an explanation of "thick description" and "thick translation", and cites Kwame Appiah's term of "thick translation" as a translation method which attempts to assimilate other cultures with intensive confrontation against cultural aggression. Hermans supports the subjectivity of the translator and indicates that "thick translation" could be a standard for translation criticism.From the point of epistemology, Hermans (2003) believes that thick translation has the potential to bring about a double dislocation: of the foreign terms and concepts, which are probed by means of an alien methodology and vocabulary; and of the describer's own terminology, which must be wrenched out of its familiar shape to accommodate both alterity and similarity. His emphasis on this double dislocation also serves to make it clear that he perceived thick translation as a methodology which could be utilized to critique the effectiveness of translations to convey cultural depth and meaning, and not as a generalized form of description or translation. For guiding practical translation, thick translation also seen as a tool for cross-cultural translation studies, in thick translation not only could avoid the dullness of terms in translation studies and the reduction in format performance, but also can create more colorful diversified vocabulary.

Although Appiah is referring specially to the problems involved tin translating African proverbs it is clear that the term may be used applied to any TT which contains a large amount of explanatory material, whether in the form of footnotes, glossaries or an extended introduction. The purpose of providing such voluminous backgrounds information is to engender in the TT reader a deeper respect for the source culture and a greater appreciation for the way that people of other backgrounds have thought and expressed themselves. (Shuttleworth \& Cowie, 2004)

In China, the study of " thick translation" has drawn extensive attention since it was introduced into domestic translation circle. Professor Martha Cheung (2003) from Hong Kong Baptist University proposed that "thick translation" is a way of cultural reproduction, and in her translating process of An Anthology of Chinese Discourse on Translation Vol.1: From Earliest Times to the Buddhist Project, this translation strategy was fully utilized. The translators present rich connotation of traditional Chinese translation theories through translation, note and commentary in various way. Duan Feng (2006) argues that thick translation is a common method in translation practice, and this theory comes from the theory of deep description in cultural anthropology and the theory of historical context in neo-historicism. Sun Ningning (2010) explores the relationship between translation and cultural anthropology with the theory of thick description of American cultural anthropologist Clifford Geertz, and points out that the essence of thick translation from the perspective of cultural anthropology is translation with explanations.Zhao Yong (2010) combined the theory of thick translation with hermeneutics theory to comparative analysis translation of allusions of Walden Lake in several different versions. Zhang Yan and Hu Weiping (2011) suggest that contextualization should be emphasized in thick translation from their study about cultural translation in cultural anthropology. That is, "thick translation" is "the only way of cultural exchange, and this road of cultural translation will become more and more smooth as mutual understanding among different cultures improved." Wang Xueming and Yang Zi (2012) believe that thick translation is "an important way of cultural exchange that has a positive reference value for carrying forward Chinese culture today and for translating and introducing Chinese cultural classics into the world." Liang Yan (2012) comprehensively introduces Appiah's conception of translatology and explains that the core of thick translation theory is to use annotations and notes to translate source language texts into richer cultural and linguistic environments. Qian Yingying (2012) analyzes the English translation of Tess of Durbuy by Zhang Gu Ruo, she clarifies the function and form of thick translation, then emphasizes the guiding function of thick translation theory in literary translation. On the basis of thick translation theory. Huang Lin (2013) studies the phenomenon of thick translation in Knoblock's English version of Xunzi and explores the positive significance of thick translation theory. Ge Houwei (2017) proceeds with the translation of minority cultural classics to explore and expand the practicality of thick translation theory.

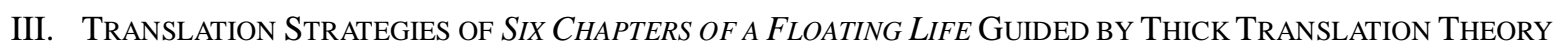

Thick translation theory holds that annotation is the translator's deliberate consideration of what he already knows. The ways to add it to the translation text fall into two main categories: intratextual annotation and extratextual annotation. The reason why Lin translated Six Chapters of a Floating Life is so meaningful that it not only perfectly reproduces the language, thoughts, aesthetic connotations and leisure pleasures of the couple's life, but also reflects the purpose of dissemination and promotion of Chinese culture. The possible reading obstacles for Western readers are removed by adding certain annotations and notes to the translation.

\section{A. Intratextual Annotation}

Intratextual annotation, as its name implies, is a comment added to the text. There are a lot of historical backgrounds and cultural and customs involved in Six Chapters of a Floating Life. Adopting literal translation only would hinder the 
readers' comprehension of the Chinese traditional culture connotation while the adaptation of domestication would result in cultural default. The annotation in the translated text could solve this problem, and it not only affects the original text and meaning, but also increases the reader's understanding of the source culture. Intratextual annotation usually appear in parentheses.

1. Traditional clan relationship

There are a large number of cultural vocabularies that express the relationship between traditional family clan in China. Such as, Chinese may use "Bo, Zhong, Shu, Ji" to show the order of seniority among the brothers, and the "Biao" and "Tang" to express the different cousinship with paternal family or maternal family. These culturally-loaded words of clan relationships lack their equivalents in English, so Lin Yutang uses the following methods when dealing with these words:

Example 1:

Source Text: 时余有表兄王荩臣一子名曰暳石，愿得青君为媳妇。

Target Text: There was a cousin of mine (the son of my paternal aunt), by the name of Wang Chinch'en, who had a son called Yunshih, for whom he wished to secure the hand of my daughter.

Analysis: In English, the word "cousin" can refer to a brother or sister, elder or younger, male or female, from paternal or maternal side. It is quite different with Chinese words expressing cousinship. The texts in parentheses are added to the translation to further explain the cousin's relationship that the man is the son of paternal aunt, so that the readers could have a general understanding of the relation.

Example 2:

Source Text: 是年冬, 值其堂姊出阁, 余又随母往。

Target Text: In the winter of that year, one of my girl cousins, (the daughter of another maternal uncle of mine) was going to get married and I again accompanied my mother to her maiden home.

Analysis: In this sentence, Lin Yutang not only pointed out that it was a female relative, but also used strategy of annotation to indicate that the girl is the daughter of the author's maternal uncle, which clearly illustrates the kinship and facilitates the understanding of the readers.

2. Geographic names

Six Chapters of Floating Life tells the story of the author's journey through various places, among which there are many geographic names. And some geographical names are different from what they used to be in ancient times. In order to facilitate the readers' further understanding of China's territory, Lin Yutang adopts the method of intratextual annotation.

Example 3:

Source Text: .....受业于武林赵省斋先生门下。

Target Text: ...... I was under the tutorship of Chao Shengtsai of Wulin [ Hangchow].

Analysis: Hangzhou was once called "Wulin", so Lin Yutang made notes here to enable English readers to find the correspondence between ancient and modern geographic names.

Example 4:

Source Text : 庚戌之春, 予又随侍吾父于刊江幕中。

Target Text : In the spring of 1790, I again accompanied my father to the magistrate's office at Hankiang [Yangchow].

Analysis: In addition to supplement explanation of the geographic names that are different in the ancient and modern times, Lin Yutang also gave an explanation of "Kan Jiang" that it was located in present Yangzhou. Such examples are beyond count in this book, like "Zhenzhou" is translated as Chengchow [Icheng, Kiangsu]; "Lingnan" is translated as Lingnan [in Kwangtung] and so on.

3. Perfumes names

Example 5:

Source Text : 芸尝以沉速等香....

Target Text : Yun used to burn aloes-wood and Shuhsiang [a kind of fragrant wood from Cambodia].

Example 6:

Source Text : 佛手忌醉鼻嗅, 嗅则易烂。

Target Text : Another thing, the "buddha's fingers" [a variety of citron] should not be smelt by a drunken man, or it would easily not.

Analysis: Shuhsiang and buddha's fingers are all names of perfumes. Simple transliteration or literal translation might cause some cultural misunderstanding, so the translator supplies annotation to specifically explain what it is and this could be closer to the original text.

\section{B. Extratextual Annotation}

The loaded annotation means to introduce the original culture in detail according to the needs of the text, and solves possible vacuum points in the semantic transformation to facilitate textual coherence in the translation. In the English version of Six Chapters of Floating Life, Lin took footnote as the main form of annotation outside the text.

1. Traditional cultural words 
Traditional cultural words can be found everywhere in Six Chapters of Floating Life. As the required explanation may be so long as to affect the text format, the translator chooses to add footnotes. Such as:

Example 7:

Source Text: 是年七夕, 芸设香烛瓜果, 同拜天孙于我取轩中。

Target Text: On the seventh night of seventh moon of the year, Yun prepared incense, candles and some melons and other fruits, so that we might together worship the Grandson of Heaven in the Hall ${ }^{1}$ called "After My Heart."

${ }^{1}$ The seventh day of the seventh moon is the only day in the year when the pair of heavenly lovers, the Cowherd and the Spinster ("Grandson of Heaven"), are allowed to meet each other across the Milky Way._- Tr.

Analysis: The Grandson of Heaven is the Vega, a name of constellation. It is recorded that "Spinster, is the Grandson of Heaven" in The Historical Records: Crown Books. The translator first translated literally, but in the face of possible cultural errors, he proceeds to use footnotes to explain that Grandson of Heaven refers to the day when the Cowherd and Spinster meet each other. It not only restores the semantics of the original text, but also maximizes the transmission of traditional cultural connotations.

Example 8:

Source Text: 清明日, 先生春祭扫墓, 挈余同游。

Target Text: On the ch'ingming festival ${ }^{1}$, my tutor was going to visit his ancestral grave and brought me along.

${ }^{1}$ A festival which falls on any unfixed date somewhere round the middle part of the spring months. On this day people are accustomed to paying their visits to their ancestral tombs in the country.

Analysis: Ching Ming is one of the traditional Chinese festivals. During the era of Lin, foreigners knew little about China, let alone the specific festivals. The translator explained here that on this day of Ching Ming, people worshiped their ancestors and clean their ancestors' graves. For the context, he explained the traditional festival of Ching Ming and took over the following text.

2. Geographical cultural words

Geographical cultural words are also commonplace in the book. To guide foreign readers to know Chinese regions, the translator supplements geographical knowledge more specifically.

\section{Example 9:}

Source Text : 虽不能远游五岳, .....

Target Text : Even if I cannot accompany you to the Five Sacred Mountains ${ }^{1}$ then,......

${ }^{1}$ The Five Scared Mountains are : (1) "Taishan, the East Scared Mountains (in shangtung), (2) Huashan, the West Scared Mountains (in Shensi), (3) Hengshan, the North Scared Mountains (in Shansi), (4) Hengshan, the South Scared Mountains (in Hunan) and (5) Sungshan, the Central Scared Mountains (in Honan)._- Tr.

Analysis: For the Chinese readers, "The Five Mountains" is common sense, but not for the English readers. In order to trigger interest in reading and deepen the understanding of the magnificent landscape of China, Lin made full footnote to provide a detailed information of these mountains.

\section{Example 10:}

Source Text: 馆江北四年, 一无快游可记。

Target Text: .... in which capacity I stayed four years in Kiangpei ${ }^{1}$, during which period I did not enjoy any travel worth recording.

${ }^{1}$ A collective name given to such districts in Kiangsu as lie to the Yangtze River- Yangchow, Icheng, Taichow, Taihing, Tsingking, Nantungchow, etc. being among these districts.

Analysis: Jiangbei (also named as Kiangsu) is to the north of the Yangtze River. In addition to this point, the translator specifically figures out that the jurisdiction of Jiangbei is Yangchow, Icheng, and Taichow, etc., thus not only retaining the original features of the original text, but also displaying the Chinese landscape.

3. Title cultural words

In ancient China, the title cultural words that were used to describe people were also colorful and varied.A title often contains many meanings, and shows the class status or the rank of the family.

Example 11:

Source Text: 余虽居长而行三，故上下呼芸为“三娘”，后忽呼为“三太太”。始而戏呼，继成习惯，甚至尊卑长 幼皆以“三太”呼之。

Target Text: I was born the third son of my family, although the eldest; hence they used to call Yun "san niang" at home, but this was later suddenly changed into "san t'ai t'ai." This began at first in fun, later became a general practice, and even relatives of all ranks, high and low, addressed her as "san t'ai t'ai." 1

1 "San" means number three." The meaning of "niang" and " $t$ 'ai t'ai" varies with local usage, but generally "niang” refers to a young married woman in a big household, while " $t$ ' $a i$ t'ai" suggests the mistress of an independent home.--Tr.

Analysis: In this sentence, Lin Yutang tries to explain the difference between the "niang" and " $t$ 'ai t'ai." These are two titles for married woman, one is the young and one is the mistress. However, in this text, Yun is obviously the first title, and the title of " $t$ 'ai t'ai" is for fun. Such examples are plentiful, like the "da yi'niang" which means to the oldest mistress in seniority of home; the "Si Xiaojie" maybe refer to the young girl who in rank four of a household.

4. Customs cultural words 
Custom is called that a kind of consciousness and behaviour which has a certain extent of epidemic time and popular area, whether it is official or private. And the customs cultural words can be divided into numerous parts, such as the dietary culture, costume culture, linguistic culture and so on.

\section{Example 12:}

Source Text: 壁间题咏甚多，不能记忆。但记楹对有云：

“何时黄鹤重来，且共倒金樽，浇洲渚千年芳草。但见白云飞去，更谁吹玉笛，落江城五月梅花？”

Target Text: There were a lot of poems written on the walls of the Tower, which I have all forgotten with the exception of a couplet running as follows: ${ }^{1}$

"Where the yellow stork comes again,

let's together empty the golden goblet,

pouring wine-offering

over the thousand-year green meadow on the isle.

Just look at the white clouds sailing off,

and who will play the jade flute,

sending its melodies

Down the fifth-moon plum-blossoms in the city?"

${ }^{1}$ In a Chinese couplet, which one sees everywhere in halls and parlous and temples, every word in one member must have a word of the same class but reversed tone in the corresponding position in the other member. With the exception of "the's", this can be seen in the translation given here with.--Tr.

Analysis: Couplet is the common decoration of the wall and gate in China, it is a unique cultural and artistic form of the Chinese language with a single word and a tone. Not only Lin translates the meaning of this couplet, he but also pays attention to the form and tone of the source couplet.

\section{CONCLUSION}

Lv Shuxiang, a great master of the Chinese language, points out that "necessary annotations should be included in the translation work." In combination with the thick translation theory, Lin Yutang's annotation awareness in the translation of Six Chapters of Floating Life is obvious. The translation of Chinese classics is not only a way for readers who do not understand the original to know the content and style of the original text, but also an important way to convey culture. Translators should try their best to make the target text similar in semantics and equivalent in style to the source text, to promote the essence of Chinese traditional culture to the maximum extent. The translation of classics into English guided by the thick translation theory, on the one hand, removes reading obstacles caused by cultural differences for Western readers; on the other hand, makes the original meaning clearer, as well as shows richness and diversity of Chinese culture.

\section{REFERENCES}

[1] Appiah, K. A. (1993). Thick Translation. Calloo 4, 808-819.

[2] Duan F. (2006). Thick Description, The New Historicism and Thick Translation: Translation Studies from the Perspective of Cultural Anthropology. Journal of XiHua Normal University 2, 90-94.

[3] Ge H. W. (2017). Deep Translation Strategies of Minority Cultural Classics. Guizhou Ethnic Studies 3, 139-142.

[4] Huang L. (2013). Thick Translation -- A Case Study of John Knoblock's Translation of Xunzi. Sichuan International Studies University.

[5] Hemans, Theo. (2003). Cross-cultural Translation Studies as Thick Translation. Bulletin of the School of Oriental and African Studies 3, 380-389.

[6] Martha P.Y. Cheung. (2003). An Anthology of Chinese Discourse on Translation Vol.1: From Earliest Times to the Buddhist Project. Shanghai: Shanghai Foreign Language Education Press.

[7] Shen F. \& Lin Y. T. (1999). Six Chapters of Floating Life. Shanghai: Foreign Languages and Their Teaching.

[8] Sun N.N. (2010). The Anthology Latitude of Translation Studies: Thick Translation. Shanghai Journal of Translators 1, $14-1$.

Yuying Li was born in Nanchang, Jiangxi, China in 1964. She is currently a professor and master's supervisor in Translation Theory and Practice, Foreign Language College, Jiangxi Normal University, Nanchang City. She has published more than 50 academic papers on translating practice and theory in both Chinese and international journals. Several provincial research projects also have been hosted by her, and finished either. Professor $\mathrm{Li}$ is also dedicated into translation teaching practice, which puts out two sets of textbooks about translation.

Qi Lu was born in Poyang, Jiangxi, China in 1995. She is a postgraduate student in Translation Theory and Practice, Foreign Language College, Jiangxi Normal University, Nanchang City. 